\title{
Position Paper for the Organization of Extracorporeal Membrane Oxygenation Programs for Acute Respiratory Failure in Adult Patients
}

\author{
Alain Combes ${ }^{1}$, Daniel Brodie ${ }^{2}$, Robert Bartlett ${ }^{3}$, Laurent Brochard ${ }^{4}$, Roy Brower $^{5}$, Steve Conrad ${ }^{6}$, Daniel De Backer ${ }^{7}$, \\ Eddy Fan ${ }^{8}$, Niall Ferguson ${ }^{8}$, James Fortenberry ${ }^{9}$, John Fraser ${ }^{10}$, Luciano Gattinoni ${ }^{11}$, William Lynch ${ }^{3}$, \\ Graeme MacLaren ${ }^{12}$, Alain Mercat ${ }^{13}$, Thomas Mueller ${ }^{14}$, Mark Ogino ${ }^{15}$, Giles Peek ${ }^{16}$, Vince Pellegrino ${ }^{17}$, \\ Antonio Pesenti ${ }^{18}$, Marco Ranieri ${ }^{19}$, Arthur Slutsky ${ }^{4}$, and Alain Vuylsteke ${ }^{20}$; The International ECMO Network \\ (ECMONet)
}

${ }^{1}$ Institute of Cardiometabolism and Nutrition, Groupe Hospitalier Pitié-Salpêtrière, Pierre Marie Curie University, Paris, France; ${ }^{2}$ Columbia University, New York, New York; ${ }^{3}$ University of Michigan, Ann Arbor, Michigan; ${ }^{4}$ St. Michael's Hospital, University of Toronto, Toronto, Ontario, Canada; ${ }^{5}$ Johns Hopkins University School of Medicine, Baltimore, Maryland; ${ }^{6}$ Louisiana State University Health Sciences Center, Shreveport, Louisiana; ${ }^{7}$ Erasme Hospital, Université libre de Bruxelles, Bruxelles, Belgium; ${ }^{8}$ Toronto General Hospital, University of Toronto, Toronto, Ontario, Canada; ${ }^{9}$ Emory University School of Medicine, Atlanta, Georgia; ${ }^{10}$ The Prince Charles Hospital and The University of Queensland, Brisbane, Queensland, Australia; ${ }^{11}$ Ospedale Maggiore Policlinico, Milan, Italy; ${ }^{12} \mathrm{National}$ University Hospital, Singapore, Singapore; ${ }^{13}$ University of Angers, Angers, France; ${ }^{14}$ University of Regensburg, Regensburg,

Germany; ${ }_{17}^{15}$ Alfred I. duPont Hospital for Children, Wilmington, Delaware; ${ }^{16}$ East Midlands Congenital Heart Centre, Leicester, United Kingdom; ${ }^{17}$ The Alfred Hospital and Monash Medical Centre, Melbourne, Victoria, Australia; ${ }^{18}$ Università di Milano-Bicocca, Monza,

Italy; ${ }^{19} \mathrm{~S}$. Giovanni Battista Molinette Hospital, Turin, Italy; and ${ }^{20}$ Papworth Hospital NHS Foundation Trust, Papworth, United Kingdom

\begin{abstract}
The use of extracorporeal membrane oxygenation (ECMO) for severe acute respiratory failure (ARF) in adults is growing rapidly given recent advances in technology, even though there is controversy regarding the evidence justifying its use. Because ECMO is a complex, high-risk, and costly modality, at present it should be conducted in centers with sufficient experience, volume, and expertise to ensure it is used safely. This position paper represents the consensus opinion of an international group of physicians and associated health-care workers who have expertise in therapeutic modalities used in the treatment of patients with severe ARF, with a focus on ECMO. The aim of this paper is to provide physicians, ECMO center directors and coordinators, hospital directors, health-care organizations, and
\end{abstract}

regional, national, and international policy makers a description of the optimal approach to organizing ECMO programs for ARF in adult patients. Importantly, this will help ensure that ECMO is delivered safely and proficiently, such that future observational and randomized clinical trials assessing this technique may be performed by experienced centers under homogeneous and optimal conditions. Given the need for further evidence, we encourage restraint in the widespread use of ECMO until we have a better appreciation for both the potential clinical applications and the optimal techniques for performing ECMO.

Keywords: extracorporeal membrane oxygenation; acute respiratory distress syndrome; hospital organization; critical care networks; position article
The use of extracorporeal membrane oxygenation (ECMO) for severe acute respiratory failure (ARF) in adults is growing rapidly given recent advances in technology, although there is controversy regarding the evidence justifying its use (1-9). The recent experience in 2009 using ECMO for pandemic influenza A
(H1N1)-associated acute respiratory distress syndrome (ARDS) revealed that many centers initiated ECMO programs without significant experience and with

(Received in original form April 4, 2014; accepted in final form July 6, 2014)

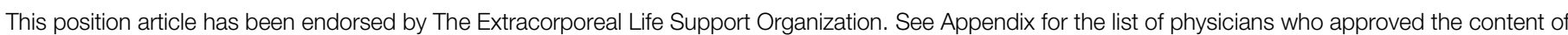
this position paper.

Author Contributions: Drafting of the article: A.C. and D.B. Critical revision of the article for important intellectual content: A.C., D.B., R. Bartlett, L.B.,

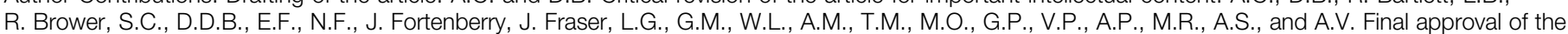
article: All signatories.

Correspondence and requests for reprints should be addressed to Alain Combes, M.D., Ph.D., Service de Réanimation Médicale, iCAN, Institute of

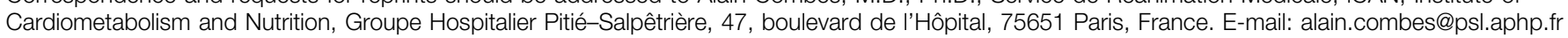

Am J Respir Crit Care Med Vol 190, Iss 5, pp 488-496, Sep 1, 2014

Copyright (C) 2014 by the American Thoracic Society

Originally Published in Press as DOI: 10.1164/rccm.201404-0630CP on July 25, 2014

Internet address: www.atsjournals.org 
variable results $(7,9-16)$. Because ECMO is a complex, high-risk, and costly modality, at present it should be conducted in centers with sufficient experience, volume, and expertise to ensure it is used safely. Additionally, further clinical trials are essential for identifying and clarifying the indications, contraindications, and techniques for use of this technology.

\section{Purpose of this Position Paper}

This position paper represents the consensus opinion of an international group of physicians and associated health-care workers who have expertise in therapeutic modalities used in the treatment of patients with severe ARF, with a focus on ECMO. The aim of this paper is to provide physicians, ECMO center directors and coordinators, hospital directors, health-care organizations, and regional, national, and international policy makers a description of the optimal approach to organizing ECMO programs for ARF in adult patients. This will help ensure that ECMO is delivered safely and proficiently at centers capable of both providing high-quality ECMO and participating in high-impact clinical research. It is of the utmost importance to ensure that future observational and randomized clinical trials assessing this technique be performed by experienced centers under homogeneous and optimal conditions Given the need for further evidence, we encourage restraint in the widespread use of ECMO until we have a better appreciation for both the potential clinical applications and the optimal techniques for performing ECMO.

\section{Definitions}

Extracorporeal life support (ECLS) systems are mechanical devices designed to temporarily support the failing heart or lungs (17). They differ from cardiopulmonary bypass systems used in the operating room for very short-term support during surgery in both their configuration and intent. The term ECMO is often used interchangeably with ECLS, as we will use it here, although it denotes a form of ECLS in which the primary purpose is to provide blood oxygenation. There are two anatomic approaches that are used to implement ECMO: venoarterial (VA) and venovenous (VV). Virtually all applications are variations on these.

- VA ECMO drains the blood from the right atrium via a femoral venous or internal jugular venous cannula or, in patients with an open chest, directly from the right atrium (17). The blood is pumped through a membrane oxygenator allowing oxygen to be added and carbon dioxide to be removed. After passing through the oxygenator, blood is then actively pumped into the arterial system either via a cannula placed in a peripheral artery, usually femoral or subclavian (closed chest), or directly into the aorta (open chest). VA ECLS is typically a high blood flow extracorporeal circuit that can pump up to $7 \mathrm{~L} / \mathrm{min}$ and provide full or partial cardiopulmonary support (18-25). VA ECMO is a closed system, which differs from standard cardiopulmonary bypass used in the operating room, which is an open system with a blood-air interface.

- VV ECMO drains blood from the venae cavae via a femoral venous or right internal jugular venous cannula (17). The blood is, once again, pumped through a membrane oxygenator; however, in this case it is returned to the venous system either via a femoral venous or right internal jugular venous cannula. A single bicaval double-lumen cannula inserted in the internal jugular vein can be used for venous drainage (26). VV ECMO is a high blood flow (up to $7 \mathrm{~L} / \mathrm{min}$ in some cases) extracorporeal circuit that may provide full or partial extracorporeal pulmonary support $(1,7,8,11,14,16,27-33)$.

- Extracorporeal carbon dioxide removal $\left(\mathrm{ECCO}_{2} \mathrm{R}\right)$ uses a venovenous (or arteriovenous) extracorporeal device at low blood flow rates $(200-1,500 \mathrm{ml} / \mathrm{min})$. This low flow rate is adequate for substantial $\mathrm{CO}_{2}$ removal but will allow only minimal blood oxygenation (34-36). Cannulae types and insertion location vary and are currently evolving. If proven to be effective, $\mathrm{ECCO}_{2} \mathrm{R}$ could potentially be used in an approach that is similar to continuous renal replacement techniques and available in most intensive care units (ICUs). This paper does not specifically address the appropriate use of $\mathrm{ECCO}_{2} \mathrm{R}$.

- Extracorporeal gas exchange refers to VV ECMO and $\mathrm{ECCO}_{2} \mathrm{R}$ techniques.

\section{Nationwide/Regional Organization of ECMO for ARF}

- ECMO is a high-risk and complex therapy that may be considered for the sickest patients with ARF. Potential indications for the use of ECMO include severe ARF from: severe ARDS, status asthmaticus, bridge to lung transplantation, post lung transplantation primary graft failure, diffuse alveolar hemorrhage, pulmonary hypertensive crisis, pulmonary embolism, severe bronchopleural fistula, and other forms of severe ARF.

- Although some evidence suggests that ECMO may be life-saving in severe ARF, the risk-to-benefit ratio of ECMO in this setting has yet to be fully elucidated, and the evidence for a benefit for less severe forms of ARF is lacking. The occurrence of ARDS severe enough to warrant consideration of ECMO (except in the context of large pandemics) may not exceed 5 to 10 cases per million population per year (our personal data, greater Paris Area, 2012). Because of this relatively infrequent level of activity, we propose that ECMO should be organized at regional and national levels to provide the best care possible in high-volume, dedicated centers, because inappropriate use of ECMO may markedly increase hospital costs and expose individual patients to important risks.

- Referral to an expert ECMO center, where ECMO is offered as part of a larger management protocol for ARF, may be associated with improved outcomes $(7,8)$. This is also consistent with the literature on the number of mechanically ventilated ICU patients, where again, the more cases a center performs, the better the outcome (37).

- Because of the many advantages of shared knowledge, training, personnel, and facilities, the organization and experience of an ECMO referral center is important in considering the case volume needed to maintain competence. Such a center should be able to maintain the skills and institutional support to justify the expense of a comprehensive program. Because ECMO for adult respiratory failure may be one component of the full spectrum of extracorporeal support provided at a given medical center, the 
presence of other groups of patients in the hospital with indications for other forms of extracorporeal circulation (cardiac failure, cardiac surgery, neonates, and so on) will facilitate such a program. Centers providing ECMO for adult respiratory failure should also maintain robust expertise in the care and ventilatory management of patients with severe ARF.

- Based on the neonatal and pediatric literature, recent data demonstrated that ECMO centers caring for more than 20 to 25 cases per year have significantly better outcomes than centers that have either 10 to 20 cases per year or fewer than 10 cases per year $(38,39)$. Moreover, the learning curve to establish competence requires at least 20 cases for optimal results (38-40).

- The question of the minimum acceptable volume for an ECMO center is an area of considerable controversy. The concept of a minimum annual volume as a surrogate for experience is a common measure in other specialties, and the pediatric ECMO literature supports the use of such thresholds. However, it is not clear that the relationship between volume and outcomes in ECMO for adult ARF demonstrates a positive inflection point in the annual volume of cases. It is also true that volume alone does not guarantee best practices or good outcomes. Other factors should be taken into account, including the cumulative experience of the center over time and the entire center's ECMO volume (adult and pediatric, respiratory and cardiac). Consideration should also be given for centers that routinely perform continuing medical education and training in ECMO, as this will serve to maintain a degree of competency over time. The annual number of patient days on ECMO may be an alternative measure of center experience. These alternative approaches to evaluating the quality of a given center are particularly important considerations for programs covering sparsely populated areas where ECMO referral to a major center is not always feasible. We therefore recommend that centers adhere to best practices, perform continuing medical education and training in ECMO, and work closely with their pediatric and cardiac ECMO colleagues.

- We recommend that for most centers, an annual volume for the entire center should be at least 20 cases per year and that at minimum of 12 ECMO cases for ARF should be performed per year. Therefore, taking into account that potential indications may not exceed 5 to 10 cases per million population per year, one such center should cover a catchment area of at least 2 to 3 million population. These recommendations, as noted, are not currently based on data in adult patients who received ECMO, and a lower case volume may be acceptable, as described above. Although further data are needed to continue to provide guidance in this area, establishing new centers in regions well served by existing high-volume ECMO centers should be discouraged.

- Centers referring patients with ARF but without rapid access to a mobile ECMO team may be trained to perform ECMO cannulation and initiation under supervision of the referral center until prompt transfer to the closest regional ECMO center can be arranged. Close coordination with the receiving ECMO center is essential to maintain quality control over indications, techniques for cannulation, and maintenance on ECMO. Indeed, the difficulty in developing and maintaining the necessary clinical expertise in a center performing a low volume of annual ECMO cases, combined with the likely diminished cost-effectiveness of a lowvolume program, must be taken into account when developing a new program. It is important that new programs establish close partnerships with more experienced, high-volume centers.

- Networks of hospitals at the local, regional or interregional level should be created around each ECMO center located in tertiary referral hospitals. Such networks have been successfully organized in the UK (41), Italy (42), and Australia (43) and have been associated with encouraging results for the treatment of the most severe forms of influenza $\mathrm{A}(\mathrm{H} 1 \mathrm{~N} 1)$-associated ARDS (7, $11,16)$. The feasibility of a network-wide system to evaluate the daily capacity for receiving patients receiving ECMO at individual centers was also demonstrated in Germany (44) and in France $(9,45)$.

- Hospitals in these networks should adhere to written standardized protocols detailing criteria for both the initiation of
ECMO (indications and exclusions) (17) as well as optimization of conventional treatments to be undertaken before the consideration of ECMO (such as lowvolume, low-pressure, lung-protective ventilation or the use of prone positioning [46] in patients with severe ARDS).

- Comprehensive plans regarding access to mobile ECMO should be created within networks.

- Referral centers and other network members should hold regular meetings to discuss network activity, including review of ECMO cases as well as those patients who were deemed inappropriate for ECMO.

\section{Mobile ECMO Team}

Each ECMO network should ideally create mobile ECMO teams to retrieve patients and to deal with patients who have critical cardiopulmonary failure refractory to conventional therapy. Their coordination would run through the tertiary ECMO referral center. This mobile team should be available 24 hours a day, 7 days a week and employ experienced personnel trained in the transport of critically ill patients, insertion of ECMO cannulae, as well as circuit and patient management. The team variably includes a mix of physicians, transport specialists, nurses, perfusionists, or other ECMO specialists. Imaging requirements at the referring hospital should be considered, and a clinician trained in echocardiography should be considered for some transfers. Portable ultrasound equipment should also be considered. Highly successful transportation of patients on cardiopulmonary support has been described for short and long distances by ambulance, helicopter, and airplane (47-53).

\section{Intrahospital Transport of the Patient Receiving ECMO}

ECMO centers should develop specific guidelines and train staff to provide 24-hour-a-day intrahospital transport of the patient receiving ECMO. Checklists should be considered for equipment (Table 1) and vital actions performed before and during transport as well as for equipment. Briefings before transport and after-action reviews are recommended. 
Table 1. Physical Facilities and Equipment Needed in the Extracorporeal Membrane Oxygenation Unit

Backup components of the ECMO system and supplies for all circuit components

Uninterrupted Power System (UPS) supporting all equipment monitors and pumps for at least $45 \mathrm{~min}$

Adequate lighting to support surgical interventions

Clamps

Surgical instrument set for revision of cannulae or exploration for bleeding complications

ECMO water heater

Doppler echocardiography machines

Fiberoptic bronchoscopes

Equipment for intrahospital transport Mobile ECMO cart

Uninterrupted power system for all mobile equipment

Mobile monitoring device

Emergency transport backpack, with ECMO clamps and emergency drugs

Wet-primed circuit available for immediate use

Definition of abbreviation: $\mathrm{ECMO}=$

extracorporeal membrane oxygenation.

\section{General Structure of an ECMO Tertiary Referral Center}

- The ECMO center should be located in a tertiary-level ICU with experience in the care of patients with severe ARF (17). The ICU should conform with the relevant national guidelines and be able to offer supportive therapy for multiorgan failure. This is particularly important for the pre-ECMO management as well as the on-ECMO handling of the lungs, which includes the interaction between the ECMO circuit and the contribution of the lungs.

- To maximize efficiency and to benefit from the expertise and experience of all professionals, ECLS programs for cardiac and respiratory failure should be located in the same institution, although not necessarily in the same ICU department.

- An ECMO referral center devoted strictly to the care of ARF might be set up independent of a cardiac ECMO program if its anticipated annual case volume exceeds 20 cases. However, as noted above, establishing new centers in regions well served by existing highvolume ECMO centers should be discouraged. Additionally, because some patients with ARF may have refractory cardiac failure necessitating the use of VA ECLS for some days during the patient's course, it is best to combine the expertise for respiratory and cardiac failure at a single center.

- The ECMO program director should be a physician with responsibility for the overall operation of the center, including assuring appropriate continued specialist training and performance, maintenance of equipment, as well as directing quality-improvement meetings and projects (17).

- Policies and procedures outlining the indications and contraindications for ECMO, clinical management of the patient receiving ECMO, maintenance of equipment, termination of ECMO therapy, and follow-up of the patient receiving ECMO should be available (17).

- The ICU must be able to provide 24-hour access to renal replacement therapy.

\section{Staffing}

- Staff involved in ECMO should meet the requirements of their subspecialty training as set forth by their specific governing national or regional board (17).

- The medical director should be a board-certified critical care specialist; cardiovascular specialist; thoracic, vascular, or trauma surgeon; or other board-certified specialist with specific training and experience in ECMO support (17).

- Every member of the staff treating patients receiving ECMO should have received specific ECMO training and demonstrate competencies on an ongoing basis (17).

- A physician comfortable with managing patients receiving ECMO should provide 24-hour on-call coverage for the patient receiving ECMO.

- Selected physicians on the ECMO team should be trained in vascular Doppler echocardiography and cardiac Doppler echocardiography for insertion, maintenance, and surveillance of the ECMO device when needed.

- In clinical settings where the patient receiving ECMO is primarily managed by the ICU nurse (the single caregiver model), the ICU nurse should be specifically trained in management of the patient receiving ECMO and the ECMO circuit (17). Fully trained ECMO personnel should be immediately available for circuit-related concerns, which may include ECMO circuit exchange.

- The ratio of nurses to patients receiving ECMO should be at least 1:1 to 1:2 (one nurse for up to two patients receiving ECMO where necessary based on unit staffing standards) depending on local or national regulations and organization.

- The ECMO team should be as selfsufficient as possible, and specifically should be trained to prime and set up the ECMO circuit. The ECMO specialist team might also be responsible for managing equipment and supplies, circuit preparation, troubleshooting, daily rounds, education, and service administration (17).

- An ECMO coordinator (typically a nurse, respiratory therapist, or perfusionist) may assist the medical director with organizing and implementing the training of the ECMO team, staffing, quality improvement, maintaining equipment and supplies, and ensuring that patient data are entered into the Extracorporeal Life Support Organization (ELSO) registry or other database.

\section{Physical Facilities and Equipment}

The equipment that should be readily available is listed in Table 1. Importantly, a wet-primed circuit should be available for immediate use around the clock, because there is some evidence that an assembled circuit can be stored for up to a few days to weeks (54) without presenting an additional risk of infection. It should be possible to change the ECMO circuit in considerably less than, but not exceeding, 15 minutes in cases of sudden malfunction. In highvolume centers, primed circuits are routinely used in much less time, a further advantage to concentrating volume.

\section{Non-ICU Support Services}

Table 2 lists medical-surgical and laboratory personnel from the permanent hospital staff who should be available 24 hours a day. The ECMO center should be able to provide emergency access $(<30 \mathrm{~min})$ to cardiovascular or thoracic surgery, abdominal surgery, 
Table 2. Non-Intensive Care Unit Support Services

\begin{tabular}{l} 
Medical-surgical staff with emergency \\
access (<30 min) \\
Cardiovascular or thoracic surgery \\
Abdominal surgery \\
Esophagogastroduodenal endoscopic \\
interventions \\
Interventional radiology including specific \\
competencies in vascular embolization \\
Medical-surgical staff needed 24 h/d \\
Cardiology, with transthoracic and \\
transesophageal echocardiography \\
Anesthesiology \\
Pulmonology \\
Neurology \\
Neurosurgery \\
Nephrology \\
Gastroenterology \\
Ear nose throat surgery \\
Obstetrics \\
General radiology for emergency \\
ultrasound and CT scanning \\
Pharmacy \\
Laboratory staff needed 24 h/d \\
Blood gas laboratory \\
Blood chemistry and hematologic testing \\
laboratory \\
Blood coagulation testing laboratory \\
Blood bank with rapid blood product \\
delivery capacity \\
Microbiology laboratory \\
\hline
\end{tabular}

esophagogastroduodenal endoscopic interventions, and interventional radiology.

A biomedical engineer should maintain ECMO equipment on a regular basis. Staff responsible for data collection should maintain the appropriate databases.

Nonemergent services, such as pastoral and palliative care or other patient and family support services, should be available.

\section{Staff Training and Continuing Education}

- Members of the ECMO staff should receive regular training and education on theoretical and practical aspects of ECMO support. Participation of staff members to this continuing education program should be recorded and their proficiency evaluated (17).

- It is recommended that team members not involved in ECMO management for prolonged periods of time go through a retraining process as defined by the ECMO program (17).

- All staff members caring for patients receiving ECMO should be trained in emergency procedures in case of sudden circuit failure or other events that require emergent discontinuation of ECMO support.

- There should be clearly articulated delineations of responsibilities for who manages specific aspects of the patient care, including anticoagulation, blood component transfusions, ECMO pump speed adjustments, sweep gas flow rate and mechanical ventilator changes, ECMO cannula securing, and wound management. Personnel responsible for these components of care should be specifically trained and internally credentialed to be part of the ECMO team.

\section{Program Evaluation and Quality Assurance}

- The multidisciplinary ECMO Team should have quality assurance review procedures in place for annual internal ECMO program evaluation (17).

- Each ECMO center should hold formal meetings on a routine basis to analyze its activity and review its equipment needs. Minutes to these meetings should be accessible for review (17).

- Meetings, which include the referral center and non-ECMO performing centers within the ECMO network, should be held regularly to discuss and report the activities of the network (17).

- A prompt review of any major complication or death should be held both with ECMO team members and with the responsible Morbidity and Mortality committee in the hospital, if available. These reviews should be conducted under the relevant quality assurance laws for the location (e.g., state or province) where the center is located (17).

- Morbidity and mortality meetings should be held rapidly to review any major complication or death related to ECMO support. These meetings should adhere to relevant quality-assurance regulations of the state in which the center is located (17).

- Formal clinical-pathological case reviews with a multidisciplinary approach should be conducted regularly.

- Records documenting maintenance of equipment and supplies should be kept (17).

- An Annual Data Report summarizing the center's collected data regarding ECMO indications and results should be available for quality assurance review.

- ECMO centers are strongly encouraged to submit their data to large national or international databases, such as the ELSO registry (55), to cross-analyze their results with other national and international institutions.

- Regional and national accreditation organizations should be created to evaluate ECMO programs regularly. Centers with poorer than expected results should be encouraged to engage in extensive practice evaluation and improvement strategies.

- There should be an ongoing mechanism to assure sustainability of the program, with financial performance evaluated based on the anticipated business plan. This review should be constructed to identify strengths and weaknesses within the program to help ensure its sustainability.

- We recommend that new programs create an advisory committee consisting of experts from outside the institution to assist with program development and quality review. Such a committee could provide oversight for approximately the first 1 to 2 years after launching a program, depending on the volume and success of the program.

\section{Patient Follow-up}

Each ECMO center should consider a follow-up program for patients receiving ECMO with establishment of customized, patient-centered, rehabilitation programs that might help improve long-term outcomes.

\section{Research}

There is a clear need for further randomized, controlled trials and other high-level evidence with respect to the use of ECMO in ARF. These data will help guide clinicians with respect to specific indications and contraindications of the various techniques. As the number of ECMO cases is relatively small at each center, national and international organizations of ECMO centers (such as ELSO and the International ECMO Network) are vital to promote research activity and further advance our knowledge. The International ECMO 
Network is a growing consortium of ECMO-proficient centers and individuals dedicated to undertaking high-quality, highimpact research in the field. By ensuring that expert centers adhere to current best practices for the organization and conduct of their ECMO programs, this group hopes to foster an environment conducive to the highest-quality evidence.

The currently ongoing ECMO to Rescue Lung Injury in Severe ARDS (EOLIA) trial (NCT01470703) (56), an international multicenter, randomized controlled trial comparing mechanical ventilation with or without ECMO in cases of severe ARDS, is a very good example of the ECMO community coming together to build on the current body of literature. The International ECMO Network hopes to expeditiously and responsibly support further research in various applications of ECMO in all forms of ARF.

\section{Conclusions}

The role of ECMO for patients with severe ARF has not been definitively established, and further studies are needed to evaluate its impact (56). The standardization of current best practices and the accumulation of experience at high-quality centers will facilitate the conduct of future research. In the meantime, optimization of conventional treatments (such as low-volume, lowpressure, lung-protective ventilation or prone positioning) should always be undertaken before considering ECMO in patients with severe ARDS. Because the successful delivery of ECMO requires highly experienced staff and a minimum number of cases per year, organization of ECMO programs on a regional or national level is needed to provide the best, safest, and most efficient care possible to the population. Local, regional, or interregional networks of hospitals with a mobile ECMO team should ideally be created around each ECMO center; such a system has recently successfully been organized in a few countries (41-43). Staff training and continuing education as well as regular audits evaluating program performance should be routinely organized to assure quality. We believe that this initiative will result in better quality of care, although it will require energy and motivation to encompass many logistical and political challenges. We recognize, however, that differences in hospital policies and national regulations may result in variations in the models for ECMO programs caring for patients with severe ARF.

Author disclosures are available with the text of this article at www.atsjournals.org.

\section{References}

1. Brodie D, Bacchetta M. Extracorporeal membrane oxygenation for ARDS in adults. N Engl J Med 2011;365:1905-1914.

2. Combes A, Bacchetta M, Brodie D, Müller T, Pellegrino V. Extracorporeal membrane oxygenation for respiratory failure in adults. Curr Opin Crit Care 2012;18:99-104.

3. Combes A, Bréchot N, Luyt CE, Schmidt M. What is the niche for extracorporeal membrane oxygenation in severe acute respiratory distress syndrome? Curr Opin Crit Care 2012;18:527-532.

4. Hubmayr RD, Farmer JC. Should we "rescue" patients with 2009 influenza $A(\mathrm{H} 1 \mathrm{~N} 1)$ and lung injury from conventional mechanical ventilation? Chest 2010;137:745-747.

5. Morris $\mathrm{AH}$. Exciting new ECMO technology awaits compelling scientific evidence for widespread use in adults with respiratory failure. Intensive Care Med 2012;38:186-188.

6. Morris AH, Hirshberg E, Miller RR, 3rd, Statler KD, Hite RD. Counterpoint: efficacy of extracorporeal membrane oxygenation in 2009 influenza $A(H 1 N 1)$ : sufficient evidence? Chest 2010;138: 778-781. [Discussion pp. 782-784.]

7. Noah MA, Peek GJ, Finney SJ, Griffiths MJ, Harrison DA, Grieve R, Sadique MZ, Sekhon JS, McAuley DF, Firmin RK, et al. Referral to an extracorporeal membrane oxygenation center and mortality among patients with severe 2009 influenza $\mathrm{A}(\mathrm{H} 1 \mathrm{~N} 1)$. JAMA 2011;306: 1659-1668.

8. Peek GJ, Mugford M, Tiruvoipati R, Wilson A, Allen E, Thalanany MM, Hibbert CL, Truesdale A, Clemens F, Cooper N, et al.; CESAR trial collaboration. Efficacy and economic assessment of conventional ventilatory support versus extracorporeal membrane oxygenation for severe adult respiratory failure (CESAR): a multicentre randomised controlled trial. Lancet 2009;374:1351-1363.

9. Pham T, Combes A, Rozé H, Chevret S, Mercat A, Roch A, Mourvillier B, Ara-Somohano C, Bastien O, Zogheib E, et al.; REVA Research Network. Extracorporeal membrane oxygenation for pandemic influenza $\mathrm{A}(\mathrm{H} 1 \mathrm{~N} 1)$-induced acute respiratory distress syndrome: a cohort study and propensity-matched analysis. Am J Respir Crit Care Med 2013;187:276-285.

10. Roch A, Lepaul-Ercole R, Grisoli D, Bessereau J, Brissy O, Castanier M, Dizier S, Forel JM, Guervilly C, Gariboldi V, et al. Extracorporeal membrane oxygenation for severe influenza $A(H 1 N 1)$ acute respiratory distress syndrome: a prospective observational comparative study. Intensive Care Med 2010;36:1899-1905.
11. Davies A, Jones D, Bailey M, Beca J, Bellomo R, Blackwell N, Forrest P, Gattas D, Granger E, Herkes R, et al.; Australia and New Zealand Extracorporeal Membrane Oxygenation (ANZ ECMO) Influenza Investigators. Extracorporeal membrane oxygenation for 2009 influenza A (H1N1) acute respiratory distress syndrome. JAMA 2009;302:1888-1895.

12. Bonastre J, Suberviola B, Pozo JC, Guerrero JE, Torres A, Rodríguez A, Martín-Loeches I; SEMICYUC-CIBERES-REIPI working group. Extracorporeal lung support in patients with severe respiratory failure secondary to the 2010-2011 winter seasonal outbreak of influenza A (H1N1) in Spain [in Spanish]. Med Intensiva 2012;36:193-199.

13. Holzgraefe B, Broomé M, Kalzén H, Konrad D, Palmér K, Frenckner B. Extracorporeal membrane oxygenation for pandemic H1N1 2009 respiratory failure. Minerva Anestesiol 2010;76:1043-1051.

14. Schmidt M, Zogheib E, Rozé H, Repesse X, Lebreton G, Luyt CE, Trouillet JL, Bréchot N, Nieszkowska A, Dupont H, et al. The PRESERVE mortality risk score and analysis of long-term outcomes after extracorporeal membrane oxygenation for severe acute respiratory distress syndrome. Intensive Care Med 2013;39:1704-1713.

15. Takeda S, Kotani T, Nakagawa S, Ichiba S, Aokage T, Ochiai R, Taenaka N, Kawamae K, Nishimura M, Ujike Y, et al.; Committee of Crisis Control, the Japanese Society of Respiratory Care Medicine and Committee of Pandemic H1N1 Surveillance, the Japanese Society of Intensive Care Medicine. Extracorporeal membrane oxygenation for 2009 influenza $A(\mathrm{H} 1 \mathrm{~N} 1)$ severe respiratory failure in Japan. J Anesth 2012;26:650-657.

16. Patroniti N, Zangrillo A, Pappalardo F, Peris A, Cianchi G, Braschi A, lotti GA, Arcadipane A, Panarello G, Ranieri VM, et al. The Italian ECMO network experience during the 2009 influenza $A(H 1 N 1)$ pandemic: preparation for severe respiratory emergency outbreaks. Intensive Care Med 2011;37:1447-1457.

17. Extracorporeal Life Support Organization. ELSO guidelines [accessed 2014 Mar 14]. Available from: http://www.elsonet.org

18. Baffes TG, Fridman JL, Bicoff JP, Whitehill JL. Extracorporeal circulation for support of palliative cardiac surgery in infants. Ann Thorac Surg 1970;10:354-363.

19. Bartlett RH, Roloff DW, Custer JR, Younger JG, Hirschl RB. Extracorporeal life support: the University of Michigan experience. JAMA 2000;283:904-908.

20. Chen YS, Chao A, Yu HY, Ko WJ, Wu IH, Chen RJ, Huang SC, Lin FY, Wang SS. Analysis and results of prolonged resuscitation in cardiac arrest patients rescued by extracorporeal membrane oxygenation. J Am Coll Cardiol 2003;41:197-203. 
21. Combes A, Leprince P, Luyt CE, Bonnet N, Trouillet JL, Léger P, Pavie A, Chastre J. Outcomes and long-term quality-of-life of patients supported by extracorporeal membrane oxygenation for refractory cardiogenic shock. Crit Care Med 2008;36:1404-1411.

22. Dalton HJ, Siewers RD, Fuhrman BP, Del Nido P, Thompson AE, Shaver MG, Dowhy M. Extracorporeal membrane oxygenation for cardiac rescue in children with severe myocardial dysfunction. Crit Care Med 1993;21:1020-1028.

23. Dembitsky WP, Moreno-Cabral RJ, Adamson RM, Daily PO. Emergency resuscitation using portable extracorporeal membrane oxygenation. Ann Thorac Surg 1993;55:304-309.

24. Muehrcke DD, McCarthy PM, Stewart RW, Foster RC, Ogella DA, Borsh JA, Cosgrove DM III. Extracorporeal membrane oxygenation for postcardiotomy cardiogenic shock. Ann Thorac Surg 1996;61: 684-691.

25. Rastan AJ, Dege A, Mohr M, Doll N, Falk V, Walther T, Mohr FW. Early and late outcomes of 517 consecutive adult patients treated with extracorporeal membrane oxygenation for refractory postcardiotomy cardiogenic shock. J Thorac Cardiovasc Surg 2010;139:302-311.e1.

26. Javidfar J, Brodie D, Wang D, Ibrahimiye AN, Yang J, Zwischenberger JB, Sonett J, Bacchetta M. Use of bicaval dual-lumen catheter for adult venovenous extracorporeal membrane oxygenation. Ann Thorac Surg 2011;91:1763-1768. [Discussion p. 1769.]

27. Bartlett RH. Extracorporeal life support in the management of severe respiratory failure. Clin Chest Med 2000;21:555-561.

28. Beiderlinden M, Eikermann M, Boes T, Breitfeld C, Peters J. Treatment of severe acute respiratory distress syndrome: role of extracorporeal gas exchange. Intensive Care Med 2006;32:1627-1631.

29. Brogan TV, Thiagarajan RR, Rycus PT, Bartlett RH, Bratton SL. Extracorporeal membrane oxygenation in adults with severe respiratory failure: a multi-center database. Intensive Care Med 2009;35:2105-2114.

30. Lewandowski K, Rossaint R, Pappert D, Gerlach H, Slama KJ, Weidemann H, Frey DJ, Hoffmann O, Keske U, Falke KJ. High survival rate in 122 ARDS patients managed according to a clinical algorithm including extracorporeal membrane oxygenation. Intensive Care Med 1997;23:819-835.

31. Lindén V, Palmér K, Reinhard J, Westman R, Ehrén H, Granholm T, Frenckner B. High survival in adult patients with acute respiratory distress syndrome treated by extracorporeal membrane oxygenation, minimal sedation, and pressure supported ventilation. Intensive Care Med 2000;26:1630-1637.

32. MacLaren G, Combes A, Bartlett RH. Contemporary extracorporeal membrane oxygenation for adult respiratory failure: life support in the new era. Intensive Care Med 2012;38:210-220.

33. Hill JD, O'Brien TG, Murray JJ, Dontigny L, Bramson ML, Osborn JJ, Gerbode F. Prolonged extracorporeal oxygenation for acute post-traumatic respiratory failure (shock-lung syndrome). Use of the Bramson membrane lung. N Engl J Med 1972;286: 629-634.

34. Bein T, Weber-Carstens S, Goldmann A, Müller T, Staudinger T, Brederlau J, Muellenbach R, Dembinski R, Graf BM, Wewalka M, et al. Lower tidal volume strategy $(\approx 3 \mathrm{ml} / \mathrm{kg})$ combined with extracorporeal $\mathrm{CO} 2$ removal versus 'conventional' protective ventilation $(6 \mathrm{ml} / \mathrm{kg})$ in severe ARDS: the prospective randomized Xtravent-study. Intensive Care Med 2013;39:847-856.

35. Iglesias M, Martinez E, Badia JR, Macchiarini P. Extrapulmonary ventilation for unresponsive severe acute respiratory distress syndrome after pulmonary resection. Ann Thorac Surg 2008;85: 237-244. [Discussion p. 244.]

36. Terragni PP, Del Sorbo L, Mascia L, Urbino R, Martin EL, Birocco A, Faggiano C, Quintel M, Gattinoni L, Ranieri VM. Tidal volume lower than $6 \mathrm{ml} / \mathrm{kg}$ enhances lung protection: role of extracorporeal carbon dioxide removal. Anesthesiology 2009;111:826-835.

37. Kahn JM, Goss CH, Heagerty PJ, Kramer AA, O'Brien CR, Rubenfeld GD. Hospital volume and the outcomes of mechanical ventilation. N Engl J Med 2006;355:41-50.

38. Freeman CL, Bennett TD, Casper TC, Larsen GY, Hubbard A, Wilkes J, Bratton SL. Pediatric and neonatal extracorporeal membrane oxygenation: does center volume impact mortality? Crit Care Med 2014;42:512-519.
39. Karamlou T, Vafaeezadeh M, Parrish AM, Cohen GA, Welke KF, Permut L, McMullan DM. Increased extracorporeal membrane oxygenation center case volume is associated with improved extracorporeal membrane oxygenation survival among pediatric patients. J Thorac Cardiovasc Surg 2013;145:470-475.

40. Jen HC, Shew SB. Hospital readmissions and survival after nonneonatal pediatric ECMO. Pediatrics 2010;125:1217-1223.

41. NHS. NICE guidance [accessed 2014 Aug 12]. Available from: http:// www.Nice.Org.Uk/guidance/ipg391/

42. ECMOnet [accessed 2014 Mar 14]. Available from: http://www. Ecmonet.Org/

43. Ministry of Health, NSW. Critical care tertiary referral networks and transfer of care (adults) [accessed 2014 Mar 14]. Available from: http://www0.Health.Nsw.Gov.Au/policies/pd/2010/pdf/pd2010_021. Pdf

44. Weber-Carstens S, Goldmann A, Quintel M, Kalenka A, Kluge S, Peters J, Putensen C, Müller T, Rosseau S, Zwißler B, et al. Extracorporeal lung support in H1N1 provoked acute respiratory failure: the experience of the German ARDS Network. Dtsch Arztebl Int 2013; 110:543-549.

45. Richard JC, Pham T, Brun-Buisson C, Reignier J, Mercat A, Beduneau G, Régnier B, Mourvillier B, Guitton C, Castanier M, et al.; the REVA study group. Interest of a simple on-line screening registry for measuring ICU burden related to an influenza pandemic. Crit Care 2012;16:R118.

46. Guérin C, Reignier J, Richard JC, Beuret $P$, Gacouin A, Boulain T, Mercier E, Badet M, Mercat A, Baudin O, et al.; PROSEVA Study Group. Prone positioning in severe acute respiratory distress syndrome. N Engl J Med 2013;368:2159-2168.

47. Beurtheret S, Mordant P, Paoletti X, Marijon E, Celermajer DS, Léger $P$, Pavie A, Combes A, Leprince P. Emergency circulatory support in refractory cardiogenic shock patients in remote institutions: a pilot study (the cardiac-RESCUE program). Eur Heart J 2013;34:112-120.

48. Foley DS, Pranikoff T, Younger JG, Swaniker F, Hemmila MR, Remenapp RA, Copenhaver W, Landis D, Hirschl RB, Bartlett RH. A review of 100 patients transported on extracorporeal life support. ASAIO J 2002;48:612-619.

49. Forrest $P$, Ratchford J, Burns $B$, Herkes R, Jackson A, Plunkett $B$, Torzillo P, Nair P, Granger E, Wilson M, et al. Retrieval of critically ill adults using extracorporeal membrane oxygenation: an Australian experience. Intensive Care Med 2011;37:824-830.

50. Lebreton G, Sanchez B, Hennequin JL, Resière D, Hommel D, Léonard $C$, Mehdaoui $H$, Roques $F$. The French airbridge for circulatory support in the Carribean. Interact Cardiovasc Thorac Surg 2012;15:420-425.

51. Lindén V, Palmér K, Reinhard J, Westman R, Ehrén H, Granholm T, Frenckner B. Inter-hospital transportation of patients with severe acute respiratory failure on extracorporeal membrane oxygenation-national and international experience. Intensive Care Med 2001;27:1643-1648.

52. Javidfar J, Brodie D, Takayama H, Mongero L, Zwischenberger J, Sonett J, Bacchetta M. Safe transport of critically ill adult patients on extracorporeal membrane oxygenation support to a regional extracorporeal membrane oxygenation center. ASAIO J 2011;57: 421-425.

53. Isgrò S, Patroniti N, Bombino M, Marcolin R, Zanella A, Milan M, Foti G, Pesenti A. Extracorporeal membrane oxygenation for interhospital transfer of severe acute respiratory distress syndrome patients: 5-year experience. Int J Artif Organs 2011;34:1052-1060.

54. Walczak R, Lawson DS, Kaemmer D, McRobb C, McDermott P, Smigla $G$, Shearer I, Lodge A, Jaggers J. Evaluation of a preprimed microporous hollow-fiber membrane for rapid response neonatal extracorporeal membrane oxygenation. Perfusion 2005;20:269-275.

55. Zeymer U, Bauer T, Hamm C, Zahn R, Weidinger F, Seabra-Gomes R, Hochadel M, Marco J, Gitt A. Use and impact of intra-aortic balloon pump on mortality in patients with acute myocardial infarction complicated by cardiogenic shock: results of the Euro Heart Survey on PCl. Eurolntervention 2011;7:437-441.

56. ClinicalTrials.gov. Extracorporeal Membrane Oxygenation for Severe Acute Respiratory Distress Syndrome (EOLIA) trial [accessed 2014 Mar 14]. Available from: http://www.Clinicaltrials.Gov/ct2/show/ nct01470703?Term=eolia\&rank=1 
Abrams, Darryl

Agerstrand, Cara

Annich, Gail

Bacchetta, Matt

Bakker, Jan

Bals, Robert

Barandon, Laurent

Barbaro, Ryan

Barker, Julian

Barrett, Nicholas

Bartlett, Robert

Bastien, Olivier

Batchinsky, Andriy

Beca, John

Bein, Thomas

Belohlavek, Jan

Bermudez, Christian

Blum, James

Brochard, Laurent

Brodie, Daniel

Brogan, Thomas

Brower, Roy

Buscher, Hergen

Butt, Warwick

Camboni, Daniele

Cancio, Leopoldo

Cannon, Jeremy

Capellier, Gilles

Carton, Edward

Castillo Moya, Andres

Chastre, Jean

Chen, Yih-Sharng

Combes, Alain

Conrad, Steven

Cooper, David

Cox, Christopher

Dalton, Heidi

De Backer, Daniel

Delnoij, Thijs

Diaz-Guzman, Enrique

Donker, Dirk

Dupont, Hervé

El-Banayosy, Aly

Fan, Eddy

Ferguson, Niall

Finney, Simon

Fortenberry, James

Fourrier, François

Fowles, Jo-anne

Fraser, John

Frenckner, Bjorn

Garcia, Jose Perez

Gattinoni, Luciano

Gommers, Diederik

Goyal, Venkat

Gruss, Marco

Haft, Jonathan

Harris, William

Herr, Daniel

Hoopes, Charles

Ichiba, Shingo

Jacquet, Luc-Marie

Jenkins, David

Karagiannidis, Christian

Kattan, Javier

Kluge, Stefan

Korver, Erik
New York, NY

New York, NY

Ann Arbor, MI

New York, NY

Rotterdam, The Netherlands

Homburg, Germany

Bordeaux, France

Ann Arbor, MI

Manchester, UK

London, UK

Ann Arbor, MI

Lyon, France

San Antonio, TX

Auckland, New Zealand

Regensburg, Germany

Prague, Czech Republic

Pittsburgh, PA

Ann Arbor, MI

Toronto, Canada

New York, NY

Seattle, WA

Baltimore, MD

Sydney, Australia

Melbourne, Australia

Regensburg, Germany

San Antonio, TX

San Antonio, TX

Besançon, France

Dublin, Ireland

Santiago, Chile

Paris, France

Taipei, Taiwan

Paris, France

Shreveport, LA

Cincinnati, $\mathrm{OH}$

Durham, NC

Phoenix, AZ

Brussels, Belgium

Maastricht, The Netherlands

Birmingham, AL

Utrecht, The Netherlands

Amiens, France

Hershey, PA

Toronto, Canada

Toronto, Canada

London, UK

Atlanta, GA

Lille, France

Papworth, UK

Brisbane, Australia

Stockholm, Sweden

Boston, MA

Milano, Italy

Rotterdam, The Netherlands

Mumbai, India

Hanau, Germany

Ann Arbor, MI

Jefferson, LA

Baltimore, MD

Lexington, $\mathrm{KY}$

Okayama, Japan

Louvain, Belgium

Papworth, UK

Cologne, Germany

Santiago, Chile

Hamburg, Germany

Maastricht, The Netherlands da2256@columbia.edu ca2264@cumc.columbia.edu gannich@med.umich.edu mb781@columbia.edu

Jan.bakker@erasmusmc.nl

Robert.Bals@uniklinikum-saarland.de

laurent.barandon@chu-bordeaux.fr

barbaror@med.umich.edu

julianbarker@me.com

nicholas.barrett@gstt.nhs.uk

robbar@med.umich.edu

olivier.bastien@chu-lyon.fr

andriy.i.batchinsky.ctr@mail.mil

JohnBeca@adhb.govt.nz

thomas.bein@klinik.uni-regensburg.de

Jan.Belohlavek@vfn.cz

bermudezc@upmc.edu

jmblum@med.umich.edu

brochardl@smh.ca

hdb5@cumc.columbia.edu

botcho@u.washington.edu

rbrower@jhmi.edu

hergenbuscher@yahoo.de

Warwick.butt@rch.org.au

Daniele.Camboni@klinik.uni-regensburg.de

LEE.CANCIO@us.army.mil

jcannon@massmed.org

gilles.capellier@univ-fcomte.fr

ecarton@mater.ie

acastill@med.puc.cl

jean.chastre@pls.aphp.fr

yschen1234@gmail.com

alain.combes@psl.aphp.fr

SConrad@Isuhsc.edu

David.Cooper@cchmc.org

christopher.cox@duke.edu

hdalton@phoenixchildrens.com

Daniel.De.Backer@erasme.ulb.ac.be

thijs.delnoij@mumc.nl

diaze@uab.edu

D.W.Donker@umcutrecht.nl

dupont.herve@chu-amiens.fr

aelbanayosy@hmc.psu.edu

Eddy.Fan@uhn.ca

n.ferguson@utoronto.ca

s.finney@imperial.ac.uk

james.fortenberry@choa.org

ffourrier@nordnet.fr

jo-anne.fowles@nhs.net

John_Fraser@health.qld.gov.au

bjorn.frenckner@karolinska.se

JGARCIA@mgh.harvard.edu

gattinon@policlinico.mi.it

d.gommers@erasmusmc.nl

venkatgoyal@hotmail.com

Marco_Gruss@klinikum-hanau.de

haft@med.umich.edu

wharris468@aol.com

dherr@smail.umaryland.edu

charles.hoopes@uky.edu

ecmoshingo@gmail.com

luc-marie.jacquet@uclouvain.be

David.Jenkins@papworth.nhs.uk

KaragiannidisC@kliniken-koeln.de

kattan@med.puc.cl

s.kluge@uke.de

erik.korver@mumc.nl 
Langner, Oliver

Le Tulzo, Yves

Lebreton, Guillaume

Lepper, Philipp

Leprince, Pascal

Lequier, Laurance

Levy, Bruno

Levy, Mitchell

Lorusso, Roberto

Luyt, Charles-Edouard

Lynch, William

Maessen, Jos

MacLaren, Graeme

Malhotra, Poonam

Mercat, Alain

Michaels, Andrew

Morrison, Tracy

Mueller, Thomas

Nakagawa, Satoshi

Ochiai, Ryoichi

Ogino, Mark

Osborn, Erik

Ouattarra, Alexandre

Oza, Pranay

Paden, Matthew

Palmer, Palle

Papazian, Laurent

Park, Pauline

Peek, Giles

Pellegrino, Vin

Pesenti, Antonio

Philipp, Alois

Pranikoff, Thomas

Quintel, Michael

Ranieri, Marco

Reis Miranda, Dinis

Renolleau, Sylvain

Reske, Andreas

Roch, Antoine

Roeleveld, Peter

Roncon, Roberto

Rozé, Hadrien

Sappington, Penny Lynn

Schears, Gregory

Schultz, Marcus

Scott, Keith

Sin, Simon

Slutsky, Arthur

Swol, Justyna

Thiagarajan, Ravi

Valchanov, Kamen

Van Dijk, Diederik

Ventetuolo, Corey

Vuylsteke, Alain

Wanek, Sandy

Wolff, Michel

Xiaotong, Hou

Zhao, Ju

Zogheib, Elie

Zwischenberger, Jay
Freiburg, Germany

Rennes, France

Paris, France

Homburg, Germany

Paris, France

Edmonton, Canada

Nancy, France

Providence, RI

Brescia, Italy

Paris, France

Ann Arbor, MI

Maastricht, The Netherlands

Singapore

New Delhi, India

Angers, France

Portland, OR

Dayton, $\mathrm{OH}$

Regensburg, Germany

Tokyo, Japan

Tokyo, Japan

Wilmington, DE

Honolulu, $\mathrm{HI}$

Bordeaux, France

Mumbai, India

Atlanta, GA

Stockholm, Sweden

Marseille, France

Ann Arbor, MI

Leicester, UK

Melbourne, Australia

Monza, Italy

Regensburg, Germany

Wake Forest, NC

Göttingen, Germany

Torino, Italy

Rotterdam, The Netherlands

Paris, France

Leipzig, Germany

Marseille, France

Leiden, The Netherlands

Porto, Portugal

Bordeaux, France

Pittsburgh, PA

Rochester, MN

Amsterdam, The Netherlands

Wake Forest, NC

Hong Kong, China

Toronto, Canada

Bochum, Germany

Boston, MA

Papworth, UK

Utrecht, The Netherlands

Providence, RI

Papworth, UK

Portland, OR

Paris, France

Beijing, China

Beijing, China

Amiens, France

Lexington, $\mathrm{KY}$ oliverj.langner@me.com

yves.le.tulzo@chu-rennes.fr

guillaume.lebreton@psl.aphp.fr

Philipp.Lepper@uniklinikum-saarland.de

pascal.leprince@psl.aphp.fr

laurance.lequier@capitalhealth.ca

blevy5463@gmail.com

mitchell_levy@brown.edu

ro.lorusso@libero.it

charles-edouard.luyt@psl.aphp.fr

wlynch@med.umich.edu

j.g.maessen@mumc.nl

graeme_maclaren@nuhs.edu.sg

drpoonamaiims@gmail.com

a.mercat@free.fr

amichael@Ihs.org

tmorrison1@woh.rr.com

thomas.mueller@klinik.uni-regensburg.de

nakagawa-s@ncchd.go.jp

roy.ochiai@gmail.com

Mark.Ogino@nemours.org

eeosborn@netscape.net

alexandre.ouattara@chu-bordeaux.fr

drpranay.oza@gmail.com

Matthew.Paden@choa.org

kenneth.palmer@karolinska.se

Laurent.PAPAZIAN@ap-hm.fr

parkpk@med.umich.edu

giles.peek@uhl-tr.nhs.uk

V.Pellegrino@alfred.org.au

a.pesenti@hsgerardo.org

alois.philipp@klinik.uni-regensburg.de

tpraniko@wakehealth.edu

mquintel@med.uni-goettingen.de

marco.ranieri@unito.it

d.dosreismiranda@gmail.com

sylvain.renolleau@trs.aphp.fr

Andreas.Reske@medizin.uni-leipzig.de

antoine.roch@ap-hm.fr

p.p.roeleveld@lumc.nl

rra_jr@yahoo.com

hadrien.roze@chu-bordeaux.fr

sappingtonpl@ccm.upmc.edu

Schears.Gregory@mayo.edu

marcus.j.schultz@gmail.com

Ikscott@wakehealth.edu

drwcsin@gmail.com

arthurslutsky@gmail.com

justyna.swol@bergmannsheil.de

Ravi.Thiagarajan@cardiochboston.org

kamen.valchanov@nhs.net

D.vanDijk@umcutrecht.nl

corey_ventetuolo@brown.edu

a.vuylsteke@nhs.net

SWANEK@LHS.ORG

michel.wolff@bch.aphp.fr

houxiaotong_2013@163.com

zhaojucpb@163.com

zogheib.elie@chu-amiens.fr

joseph.zwischenberger@uky.edu 